\title{
Obesity and the Metabolic Syndrome in the Elderly - A Mini-Review
}

\author{
Monika Lechleitner \\ Landeskrankenhaus Hochzirl, Anna Dengel-Haus, Zirl, Austria
}

\section{Key Words}

Metabolic syndrome $\cdot$ Obesity

\begin{abstract}
The metabolic syndrome is defined as a cluster of cardiometabolic risk factors which are related to insulin resistance. Beyond the importance of each separate risk factor, the aggregation of abdominal obesity, impaired glucose metabolism, dyslipidemia and hypertension, summarized as the metabolic syndrome, characterizes individuals with a significant increase in the risk for type 2 diabetes and cardiovascular disease. In the prosperous countries of the world, the prevalence of the metabolic syndrome is about $20 \%$ in the adult population, and increases with increasing age, which is mainly attributed to the significant increase in overweight and obesity, also in elderly. Current data indicate that weightloss therapy improves physical function, quality of life and the medical complications associated with obesity. This review summarizes epidemiologic data, diagnostic criteria and the clinical importance of the metabolic syndrome, the complex pathophysiologic mechanisms involved in the development of insulin resistance in elderly, and the various therapeutic options. According to these data the identification and treatment of patients with a metabolic syndrome would be an important approach to reduce morbidity and impairments in the elderly.

Copyright $\odot 2008$ S. Karger AG, Basel
\end{abstract}

\section{Introduction}

In the prosperous countries of the world, life expectancy has revealed a continuous increase during the last decades, paralleled by an increase in age-associated diseases and disabilities. Beside aging, the high prevalence of overweight, obesity and the related co-morbidities, affecting also the elderly population, are considered as major healthcare problems [1]. Obesity causes several serious medical complications, including metabolic abnormalities, cancer, physical disability, obstructive sleep apnea syndrome and urinary incontinence [2]. Insulin resistance, as the main underlying disorder of obesity-related diseases, is more pronounced in overweight and obese individuals. The degree of insulin resistance reveals an increase with increasing age [3], and elderly are therefore at a higher risk to develop the cardiometabolic risk factors summarized as the metabolic syndrome [4, 5]. Beyond the importance of each separate risk factor, the aggregation of abdominal obesity, impaired glucose metabolism, dyslipidemia and hypertension seems to identify individuals with a significant increase in the risk for cardiovascular disease and type 2 diabetes [6-8]. In elderly patients the diagnosis of a metabolic syndrome is furthermore related to a more pronounced cognitive decline [9] and thus disability. With respect to this enhancement of the most significant health problems among people $>65$ years of age, the identification and treatment of patients with a metabolic syndrome would be an important approach to reduce morbidity and impairments in elderly. 


\section{Definition and Prevalence of the Metabolic Syndrome}

According to the original definition by Reaven [4], the most common components of the metabolic syndrome are central obesity, insulin resistance, hyperinsulinemia and glucose intolerance, dyslipidemia and hypertension. Medical conditions, such as a prothrombotic and pro-inflammatory state, fatty liver disease and obstructive sleep apnea syndrome were consecutively defined as symptoms of the metabolic syndrome [7]. The European Diabetes Epidemiology Collaborative survey analysis Of Diagnostic criteria in Europe (DECODE) study could recently demonstrate that the diagnosis of a metabolic syndrome results in a significant increase in cardiovascular and all-cause mortality, even in non-diabetic patients [6]. In general, the risk for cardiovascular events is doubled in patients with a metabolic syndrome compared to those without it; the risk for type 2 diabetes is increased for about 5-fold [7]. Various definitions of the metabolic syndrome are currently available. A majority of epidemiologic and clinical studies performed their evaluations according to the National Cholesterol Education Program Adult Treatment Panel (NCEP) criteria [10], where patients are considered to have the metabolic syndrome if they meet $\geq 3$ of 5 criteria (abdominal obesity, hypertriglyceridemia, low HDL cholesterol, high blood pressure or the use of antihypertensive medication, high fasting glucose or the use of antidiabetic medication). In the International Diabetes Federation (IDF) definition of the metabolic syndrome, abdominal obesity is considered as the central diagnostic criteria [11] (table 1). Recommendations to measure waist circumference rather than the body mass index (BMI) support the central importance of abdominal obesity in the metabolic syndrome [12].

Both of the definitions of the metabolic syndrome, NCEP-ATP III or IDF criteria, are frequently applied in clinical practice and identify patients at an increased cardiovascular risk. The application of the IDF criteria in patients with type 2 diabetes resulted - compared to the NCEP definition - in a higher estimated prevalence of the metabolic syndrome, but did not improve the prognostic value [13].

In a recently published analysis of the Italian longitudinal study of aging the diagnosis of a metabolic syndrome according to the IDF criteria showed no relationship to the risk for myocardial infarction or stroke in elderly [14]. This lack of a predictive value in an older population might be explained by the fact that the currently available definitions of the metabolic syndrome do not consider the effect of aging on the various diagnostic variables. The BMI, calculated as body weight $(\mathrm{kg})$ divided by the square meter of height, is applied as a simple method to classify weight categories. Independent of age, overweight is defined as a BMI of 25.0-29.9 and obesity as a BMI $\geq 30[15,16]$. In elderly, however, the relationship between BMI and the percentage of body fat is altered as a consequence of the age-associated loss of body height caused by compression of vertebral bodies, and the changes of body composition with a decrease in muscle mass and an increase in fat mass [2]. The age-related height modification induces a false BMI increase of $1.5 \mathrm{in}$ men and 2.5 in women. Overweight in elderly is defined as a $\mathrm{BMI} \geq 27.0$ [17], for the BMI range between 25.0 and 27.0 no increase in cardiovascular and all-cause mortality could be demonstrated [18].

Table 1. Criteria for clinical diagnosis of the metabolic syndrome

\begin{tabular}{|c|c|c|}
\hline Clinical measure & NCEP, 2001 & IDF, 2005 \\
\hline Diagnosis & 3 of the following 5 features & $\begin{array}{l}\text { increased waist circumference plus } 2 \text { of the follow- } \\
\text { ing features }\end{array}$ \\
\hline $\begin{array}{l}\text { Body weight - } \\
\text { waist circumference }\end{array}$ & $\begin{array}{l}\text { waist circumference } \geq 102 \mathrm{~cm} \text { in men or } \geq 88 \mathrm{~cm} \text { in } \\
\text { women }\end{array}$ & $\begin{array}{l}\text { waist circumference } \geq 94 \mathrm{~cm} \text { in men or } \geq 80 \mathrm{~cm} \text { in } \\
\text { women }\end{array}$ \\
\hline Lipid values & $\begin{array}{l}\text { triglycerides } \geq 150 \mathrm{mg} / \mathrm{dl} \\
\mathrm{HDL}-\mathrm{C}<40 \mathrm{mg} / \mathrm{dl} \text { in men or }<50 \mathrm{mg} / \mathrm{dl} \text { in women }\end{array}$ & $\begin{array}{l}\text { triglycerides } \geq 150 \mathrm{mg} / \mathrm{dl} \\
\mathrm{HDL}-\mathrm{C}<40 \mathrm{mg} / \mathrm{dl} \text { in men or }<50 \mathrm{mg} / \mathrm{dl} \text { in women }\end{array}$ \\
\hline Glucose & fasting glucose $\geq 110 \mathrm{mg} / \mathrm{dl}$ (includes diabetes) & fasting glucose $\geq 100 \mathrm{mg} / \mathrm{dl}$ (includes diabetes) \\
\hline Blood pressure & $\geq 130 / 85 \mathrm{~mm} \mathrm{Hg}$ & $\geq 130 / 85 \mathrm{~mm} \mathrm{Hg}$ or antihypertensive medication \\
\hline
\end{tabular}


It is widely assumed that body weight tends to increase with increasing age, peaks between the age of 50 and 59 years, and then decreases [19]. The value of these observational data remains a matter of debate regarding the bias that obese patients reveal a high premature mortality and a shorter life expectancy, compared to non-obese patients with a significantly higher chance to reach an advanced age [20]. Results from longitudinal cohort studies could demonstrate that body weight and BMI values decrease only slightly in older adults [21-23]. More conclusive data are available about the age-associated changes in body composition. Muscle mass decreases up to $40 \%$ from 20 to 70 years of age [2], fat mass increases with the predominance of abdominal fat accumulation [24], and all of these aging-associated changes result in an increased prevalence of most of the metabolic and cardiovascular abnormalities contributing to the metabolic syndrome [21, 25]. Fasting glucose, diabetes risk and systolic blood pressure values reveal a linear relationship with aging and the BMI [26].

In most industrialized countries the prevalence of the metabolic syndrome is about $20 \%$ in the overall population, and increases with increasing age. Data from the Third National Health and Nutrition Examination Survey could recently demonstrate that the presence of the metabolic syndrome is $7 \%$ in the age group of $20-29$ years, increases to $44 \%$ in the age group of 60-69 years, and is $42 \%$ in people aged 70 years or older [27].

\section{Pathophysiology}

The pathophysiology of the metabolic syndrome seems to be largely attributable to insulin resistance $[5,6]$. Aging, genetic and environmental factors, such as high calorie intake and sedentary lifestyle, increase the degree of insulin resistance. Overweight, obesity and especially a central pattern of fat accumulation are associated with insulin resistance.

Obesity is the result of a long-term positive energy balance based on complex interactions between environmental factors and the genetic background. A strong genetic influence was suggested by the results of adoption and twin studies $[28,29]$ which could demonstrate that the BMI values correlated among family members also when reared apart. Beside the rare monogenic forms of obesity, more than 100 candidate genes for common obesity in humans have been identified until now [30]. These susceptibility genes affect body weight regulation, adipocyte differentiation and metabolism. Based on this ge- netic background, environmental factors, including sedentary lifestyle, high energy intake and social aspects, enhance the risk for obesity. A recently published evaluation of the Framingham Study provides an interesting alternative explanation for the worldwide increase in the prevalence of obesity, by demonstrating that the chance of a person to become obese is significantly higher when a friend, sibling or spouse are obese [31]. The social network could be a relevant factor in the obesity epidemic.

Obesity increases the risk for various co-morbidities, and recent advances in the understanding of adipose tissue biology offer an insight into the complex pathophysiologic mechanisms (fig. 1). Various endocrine and proinflammatory products from the visceral adipose tissue, which interact with the insulin signaling cascade, could be identified [32]. Among these products, adiponectin protects from insulin resistance and cardiovascular disease [33], while free fatty acids, leptin, resistin and proinflammatory substances promote the development of insulin resistance [34]. Leptin, the product of the obesity gene, is primarily produced by the adipose tissue, regulates food intake and energy expenditure, skeletal muscle fatty acid metabolism and hepatic glucose production [35]. Most common forms of obesity are characterized by high levels of circulating leptin and leptin resistance. Leptin reveals structural similarities with pro-inflammatory cytokines, such as interleukin (IL)-6, which interferes with insulin action. Cells of the stroma vascular fraction in adipose tissue, and especially in visceral fat, are an important source of IL- 6 production [36]. Tumor necrosis factor- $\alpha$ (TNF- $\alpha)$ is a further adipocytokine which was extensively studied as a possible link between obesity, subclinical inflammation and insulin resistance. TNF- $\alpha$ impairs insulin action by inhibitory effects on the insulin signaling cascade and by suppressing the transcription of adiponectin [37]. Various new adipocytokines with effects on insulin sensitivity could be recently identified, including visfatin, which enhances the production of IL- 6 and TNF- $\alpha$ [38], retinol-binding protein4 , vaspin and omentin [39].

Beside adipocytokines, the excessive flux of fatty acids from adipose tissue is a central component in the development of the metabolic syndrome. Free fatty acids are released from adipose tissue triglycerides through the action of hormone-sensitive lipase, and from triglyceriderich lipoproteins undergoing lipolysis by lipoprotein lipase. Because both mechanisms are regulated by insulin, insulin resistance leads to a further enhancement of free fatty acid release from adipose tissue and an impaired clearance of triglyceride-rich lipoproteins [40]. Increased 
Fig. 1. Pathophysiology of the metabolic syndrome.

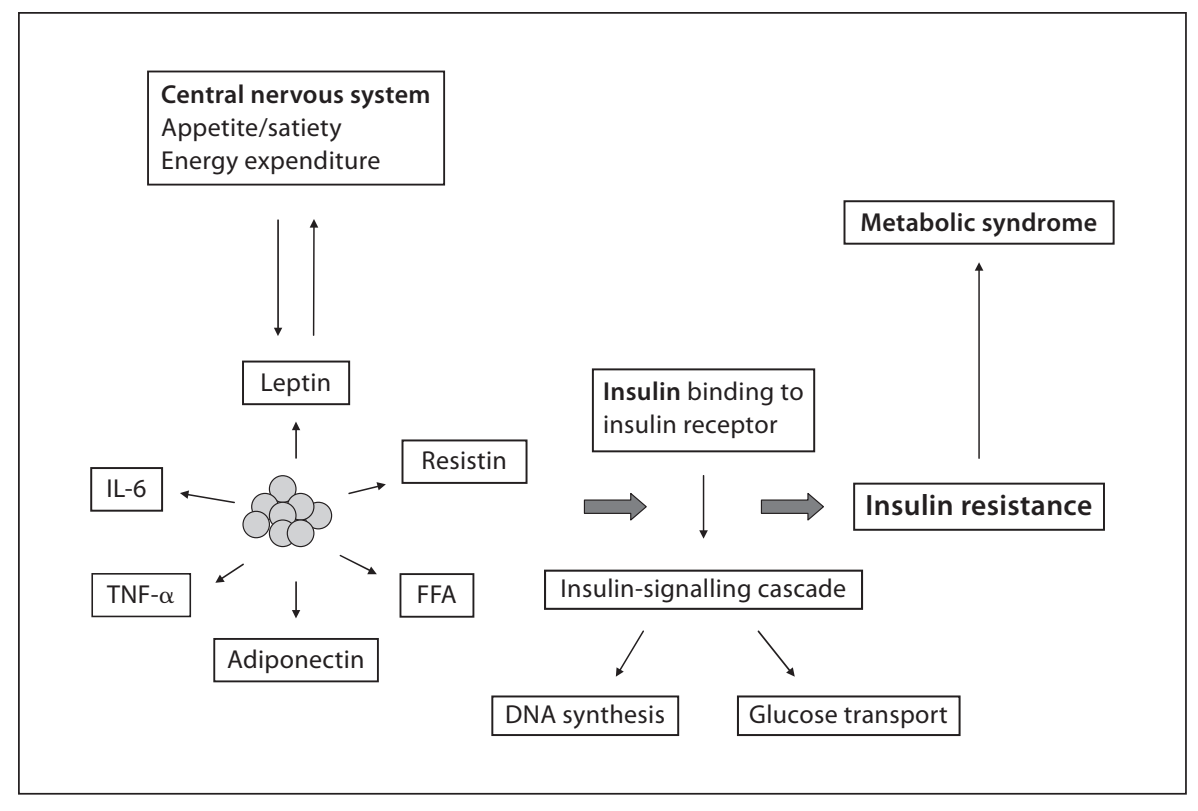

plasma levels of free fatty acids, associated with a higher degree of insulin resistance, result in an impaired inhibitory effect of insulin on hepatic glucose production and lipogenesis [40]. As a consequence, lipid deposition in ectopic sites, such as liver, skeletal muscle and pancreatic islets, can occur with a functional impairment of the specific organ (lipotoxicity) [41]. It is furthermore hypothesized that an inadequate high energy intake causes - as an initial event in the development of insulin resistance - overloading of adipose tissue, the capacity to store free fatty acids in adipocytes is exceeded, and lipids accumulate in ectopic sites (overflow hypothesis) [42]. Considering the aging-associated increase of insulin resistance, it could be speculated that aging of the adipocytes with an impaired capacity to store lipids is involved in the complex mechanisms leading to an increase in the prevalence of the metabolic syndrome in elderly [43]. The age-associated changes in body composition with a decrease in muscle mass and an increase in fat mass enhance insulin resistance [6], and are the result of complex hormonal changes, comprising a decrease in growth hormone and testosterone, and an impaired responsiveness to thyroid hormone and leptin [2, 44-46]. A further explanation for the aging-associated increase in insulin resistance is the observation of an impaired mitochondrial function and reduced cellular energy supply in elderly [47]. Defects in mitochondrial oxidative phosphorylation were found to be related to lipid accumulation in the muscle of elderly patients [48].

\section{Therapeutic Options}

Large trials could demonstrate the effectiveness of lifestyle modification in the prevention of obesity- and obesity-associated co-morbidities [49]. Especially the risk to develop type 2 diabetes reveals a strong relationship to overweight and physical inactivity. Diabetes prevention studies, such as the Finnish Diabetes Prevention Program [50] and the US Diabetes Prevention Program [51], confirmed that modest weight reduction and physical activity retard the progression from impaired glucose tolerance to overt type 2 diabetes. In the recently published 20-year follow-up evaluation of the China Da Quing Prevention Study, participants with combined lifestyle intervention showed a $51 \%$ lower incidence of type 2 diabetes during the active intervention period and a $43 \%$ lower incidence over the observation period of 20 years [52]. These favorable and sustained long-term effects of lifestyle interventions are of great importance with respect to a retarded manifestation of type 2 diabetes and thus lower risk of related disabilities in elderly. Weight loss therapy in elderly obese persons improves physical function and performance and the quality of life $[2,53]$.

In addition to weight reduction and an increase in the level of physical exercise, metformin, glitazones, statins, ACE inhibitors and sartanes were found to be effective in improving insulin sensitivity in high-risk patients [54, 55]. A modest intended weight loss of 5-15\% significantly reduces the associated excess risk in overweight and 
obese patients [55]. Because clear data about the prognostic importance of overweight and obesity in elderly persons ( $\geq 65$ years) are until now not available [2], caution is recommended regarding a pronounced weight reduction with strict target values. This critical view is supported by studies in the very elderly suggesting a protective effect of moderate overweight $[56,57]$. In a recently published meta-analysis, including 13 studies, a BMI in the range of 25-27 - and thus in the slightly overweight range - could not be confirmed as a risk factor for all-cause and cardiovascular mortality in the elderly [18]. Indices of visceral obesity - such as waist circumference - seem to be better indicators for the cardiovascular risk than the BMI $[44,58]$. Increased abdominal fat mass was found to be independently associated with the metabolic syndrome in men and women also at an advanced age of 70-79 years [59].

Weight reduction is achieved by low-calorie and lowfat diets and an increase in physical activity. The therapeutic procedures can be intensified by anti-obesity drugs, or, as an ultimate procedure and rarely performed in elderly, bariatric surgery [55]. Because most clinical trials have excluded older people [60-62], little is known about the benefits and possible disadvantages of intended weight loss by dietary programs or medication in older overweight or obese patients. Weight loss regimens that minimize muscle and bone losses are especially recommended for older obese patients in order to prevent an enhancement of the unfavorable age-related changes in body composition [2]. Physical exercise increases insulin sensitivity and is especially recommended for elderly, but has to be adapted to the individual situation. The American Cardiovascular Health Study evaluated the role of physical activity in a large group of men and women aged from 65 to 100 years, and could demonstrate that disability is strongly related to fat mass [21]. Regular and sustained physical activity improves all risk factors for the metabolic syndrome [63], while low levels of walking increase the likelihood for the metabolic syndrome also in older adults [64]. Aerobic exercise stimulates mitochondrial biosynthesis, endurance exercise training increases mitochondrial size, number, and oxidative activity in elderly patients [65].

\section{Metabolic Syndrome and Type 2 Diabetes}

The metabolic syndrome is present in a majority of obese patients with type 2 diabetes. In the treatment of type 2 diabetes, metformin and the glitazones are classi- fied as substances that increase insulin sensitivity. Metformin was applied in the Diabetes Prevention Program [51], where 648 of the 3,234 participants were older than 60 years of age. A recently published analysis of the Diabetes Prevention Program could demonstrate that lifestyle interventions and metformin reduced the development of a metabolic syndrome in high-risk patients [66]. Glitazones are antidiabetic drugs which improve insulin sensitivity through a reduction in muscle lipid content and re-distribution of lipid into adipose tissue [67]. Caution is indicated in elderly patients with respect to data about an increased rate of heart failure and an increase in bone fractures in elderly women under glitazone therapy.

New therapeutic strategies are offered by the incretin system. Glucagon-like pepetide-1 (GLP-1) is a gastrointestinal hormone that is secreted by the L-cells of the intestine after meal ingestion. GLP-1 stimulates pancreatic insulin secretion, suppresses glucagon production, prolongs gastric emptying and satiety indices in the central nervous system. Especially by reducing appetite and thus weight, GLP-1 may also improve insulin sensitivity [68]. GLP-1 has a very short half-life because it is degraded by the ubiquitous enzyme dipeptidyl-peptidase IV (DPPIV). The DPP-IV-resistant incretin mimetic exendin-4 and DPP-IV inhibitors have recently become available for clinical application. With respect to long-term safety, the full scope of the incretin effects need to be elucidated.

\section{Management of the Cardiovascular Risk in Patients with a Metabolic Syndrome}

The results of recently published statin trials show that a strict LDL cholesterol-lowering results in a significant reduction of cardiovascular morbidity and mortality, also in elderly patients [69]. Insulin resistance is related to an atherogenic lipoprotein phenotype with hypertriglyceridemia, an increase in the plasma level of apo-Bcontaining lipoproteins, a reduction of HDL cholesterol and small dense LDL particles [70]. The primary target in lipid-lowering therapy, however, remains LDL cholesterol.

Hypertension is very common in the older population, affecting up to $50 \%$ of all persons aged $>65$ years [2]. Combined antihypertensive medication is frequently necessary to lower blood pressure to the recommended goal of $<130 / 80 \mathrm{~mm} \mathrm{Hg}$ [71], and successful antihypertensive therapy results in a lower risk of stroke, cardiovascular events and heart failure [71]. The efficacy 
and safety of antihypertensive treatment regimens could be demonstrated by several trials also for elderly patients.

The cluster of cardiometabolic risk factors, summarized as the metabolic syndrome, identifies patients with a need for a more strict therapeutic management, also with the aim to prevent aging-associated diseases and disabilities. Especially in elderly, the patient's individual situation has to be considered, including the advantages, safety and possible side effects of therapeutic regimens.

\section{References}

1 Rössner S: Obesity in the elderly - a future matter of concern? Obes Rev 2001;2:183188 .

-2 Villareal DT, Apovian CM, Kushner RF, Klein S: Obesity in older adults: technical review and position statement of the American Society for Nutrition and NAASO, The Obesity Society. Am J Clin Nutr 2005;82:923-934.

3 Facchini FS, Hu N, Abbasi F, Reaven GM: Insulin resistance as a predictor of age-related diseases. J Clin Endocrinol Metab 2001;86: 3574-3578.

4 Reaven GM: Banting Lecture 1988. The role of insulin resistance in human disease. Diabetes 1988;37:1595-1607.

$\checkmark 5$ Eckel RH, Grundy SM, Zimmet PZ: The metabolic syndrome. Lancet 2005;365:14151428.

$6 \mathrm{Hu}$ G, Qiao Q, Tuomilheto J, Balkau B, Borch-Johnsen K, Pyorala K: Prevalence of the metabolic syndrome and its relation to all-cause and cardiovascular mortality in non-diabetic European men and women. Arch Intern Med 2004;164:1066-1076.

7 Grundy SM: Metabolic syndrome pandemia. Arterioscler Thromb Vasc Biol 2008;28:629632.

-8 McNeill AM, Katz R, Girman CJ, Rosamond WD, Wagenknecht LE, Barzilay JI, Tracy RP, Savage PJ, Jackson SA: Metabolic syndrome and cardiovascular disease in older people: the cardiovascular health study. J Am Geriatr Soc 2006;54:1317-1324.

$\checkmark 9$ Yaffe K: Metabolic syndrome and cognitive disorders. Alzheimer Dis Assoc Disord 2007; 21:167-171.

10 Executive Summary of the Third Report of The National Cholesterol Education Program (NCEP) Expert Panel on Detection, Evaluation, and Treatment of High Blood Cholesterol in Adults (Adult Treatment Panel III). JAMA 2001;285:2486-2497.

-11 Alberti KG, Zimmet P, Shaw J; IDF Epidemiology Task Force Consensus Group: The metabolic syndrome - a new worldwide definition. Lancet 2005;366:1059-1062.

-12 Després JP, Lemieux I: Abdominal obesity and metabolic syndrome. Nature 2006;444: 881-887.

13 Monami M, Marchionni N, Masotti G, Mannucci E: IDF and ATP-III definitions of metabolic syndrome in the prediction of all- cause mortality in type 2 diabetic patients. Diabetes Obes Metab 2007;9:350-353.

14 Motta M, Bennati E, Cardillo E, Passamonte M, Ferlito L, Malaguarnera M: The metabolic syndrome in the elderly: considerations on the diagnostic criteria of the International Diabetes Federation and some proposed modifications. Arch Gerontol Geriatr 2008 (in press).

15 World Health Organization: Obesity: Preventing and Managing the Global Epidemic. Report of a WHO Consultation on Obesity. Geneva, WHO, 1998

16 Willett WC, Dietz WH, Colditz GA: Guidelines for healthy weight. N Engl J Med 1999. 341:427-439.

17 Volkert D, Berner YN, Berry E, et al: ESPEN guidelines on enteral nutrition: geriatrics. Clin Nutr 2006;25:330-360.

18 Heiat A, Vaccarino V, Krumholz HM: An evidence-based assessment of federal guidelines for overweight and obesity as they apply to elderly persons. Arch Intern Med 2001; 161:1194-1203.

19 Harris TB, Launer LJ, Madans J, Feldman JJ: Cohort study of effect of being overweight and change in weight on risk of coronary heart disease in old age. BMJ 1997;314:17911794.

20 Manson JE, Willett WC, Stampfer MJ, Colditz GA, Hunter DJ, Hankinson SE, Hennekens $\mathrm{CH}$, Speizer FE: Body weight and mortality among women. N Engl J Med 1995;333. 677-685.

21 Grinker JA, Tucker K, Vokonas PS, Rush D: Body habitus changes among adult males from the normative aging study: relations to aging, smoking history and alcohol intake. Obes Res 1995;3:435-446.

22 Kannel WB, Gordon T, Castelli WP: Obesity, lipids, and glucose intolerance. The Framingham Study. Am J Clin Nutr 1979;32: 1238-1245.

23 Fogelholm M, Kujala U, Kaprio J, Sarna S: Predictor of weight change in middle-aged and old men. Obes Rev 2000;8:367-373.

24 Visser M, Langlois J, Guralnik JM, Cauley JA, Kronmal RA, Robbins J, Williamson JD: High body fatness, but not low fat-free mass, predicts disability in older men and women: the Cardiovascular Health Study. Am J Clin Nutr 1998;68:584-590.
25 Bo M, Sona A, Astengo M, Fiandra U, Quagliotti E, Brescianini A, Fonte G: Metabolic syndrome in older subjects: coincidence or clustering? Arch Gerontol Geriatr 2008 (in press).

26 Alexander CM, Landsman PB, Grundy SM: The influence of age and body mass index on the metabolic syndrome and its components. Diabetes Obes Metab 2008;10:246-250.

27 Ford ES, Giles WH, Dietz WH: Prevalence of the metabolic syndrome among US adults: findings from the Third National Health and Nutrition Examination Survey. JAMA 2002; 287:356-359.

28 Stunkard AJ, Sorensen TI, Hanis C, et al: An adoption study of human obesity. N Engl J Med 1986;314:193-198.

-29 Stunkard AJ, Harris JR, Pedersen NL, McClearn GE: The body mass index of twins who have been reared apart. N Engl J Med 1990;322:1483-1487.

30 Körner A, Kiess W, Stumvoll M, Kovacs P: Polygenic contribution to obesity: genomewide strategies reveal new targets. Front Horm Res 2008;36:12-36.

31 Christakis NA, Fowler JM: The spread of obesity in a large social network over 32 years. N Engl J Med 2007;357:370-374.

-32 Havel PJ: Update on adipocyte hormones; regulation of energy balance and carbohydrate/lipid metabolism. Diabetes 2004;53: S143-S151.

33 Matsuzawa Y, Funahashi T, Kimara S, Shimomura I: Adiponectin and metabolic syndrome. Arterioscler Thromb Vasc Biol 2004; 24:29-33.

34 Ridker PM: Inflammatory biomarkers and risk for myocardial infarction, stroke, diabetes and total mortality: implications for longevity. Nutr Rev 2007;65:S253-S259.

35 Dyck DJ, Heigenhauser GJ, Bruce CR: The role of adipokines as regulators of skeletal muscle fatty acid metabolism and insulin sensitivity. Acta Physiol 2006;186:5-16.

36 Grimble RF: Inflammatory status and insulin resistance. Curr Opin Clin Nutr Metab Care 2002;5:551.

37 Hotamisligil GS, Arner P, Caro JF, Atkinson RL, Spiegelman BM: Increased adipose tissue expression of tumor necrosis factor- $\alpha$ in human obesity and insulin resistance. J Clin Invest 1995;95:2409-2415. 
38 Moschen AR, Kaser A, Enrich B, et al: Visfatin, an adipocytokine with proinflammatory and immunomodulating properties. J Immunol 2007;178:1748-1758.

- 39 Gustafson B, Hammarstedt A, Andersson CX, Smith U: Inflamed adipose tissue: a culprit underlying the metabolic syndrome and atherosclerosis. Arterioscler Thromb Vasc Biol 2007;27:2276-2283.

-40 Boden R, Shulman GI: Free fatty acids in obesity and type 2 diabetes: defining their role in the development of insulin-resistance and $\beta$-cell dysfunction. Eur $\mathrm{J}$ Clin Invest 2002;32(suppl 3):14-23.

41 Friedman J: Fat in all the wrong places. Nature 2002;415:268-269.

42 Unger RM: Lipid overload and overflow: metabolic trauma and the metabolic syndrome. Themes Endocrinol Metab 2003;14: 398-403.

43 Slawik M, Vidal-Puig AJ: Lipotoxicity, overnutrition and energy metabolism in aging. Aging Res Rev 2006;5:144-154.

44 Beaufrère B, Morio B: Fat and protein redistribution with aging: metabolic considerations. Eur J Clin Nutr 2000;54(suppl):S48S53.

45 Schwartz RS: Trophic factor supplementation: effect on the age-associated changes in body composition. J Gerontol A Biol Sci Med Sci 1995;50:151-156.

-46 Moller N, O’Brien P, Nair KS: Disruption of the relationship between fat content and leptin levels with aging in humans. J Clin Endocrinol Metab 1998;83:931-934.

47 Kim J, Wei Y, Sowers JR: Role of mitochondrial dysfunction in insulin resistance. Circ Res 2008;102:401-414.

- 48 Petersen KF, Befroy D, Dufour S, Dziura J, Ariyan C, Rothman DL, DiPietro L, Cline GW, Shulman GI: Mitochondrial dysfunction in the elderly: possible role in insulin resistance. Science 2003;300:1140-1142.

49 Galani C, Schneider H: Prevention and treatment of obesity with lifestyle interventions: review and meta-analysis. Int $J$ Public Health 2007;52:348-359.

-50 Tuomilehto J, Lindström J, Eriksson JG, et al; Finnish Diabetes Prevention Study Group: Prevention of type 2 diabetes mellitus by changes in lifestyle among subjects with impaired glucose tolerance. N Engl J Med 2001; 344:1343-1350.
51 Knowler WJ, Barrett-Connor E, Fowler SE, et al; Diabetes Prevention Program Research Group: Reduction in the incidence of type 2 diabetes with lifestyle intervention or metformin. N Engl J Med 2002;346:393-403.

52 Li G, Zhang P, Wang J, Gregg EW, Yang W, Gong Q, et al: The long-term effect of lifestyle interventions to prevent diabetes in the China Da Qing Diabetes Prevention Study: a 20-year follow-up study. Lancet 2008;371: 1783-1789.

53 Jensen GL, Roy MA, Buchanan AE, Berg WB: Weight loss intervention for obese older women: improvements in performance and function. Obes Res 2004;12:1814-1820.

54 Grant RW, Meigs JB: Should the insulin resistance syndrome be treated in the elderly? Drugs Aging 2004;21:141-151.

55 Hainer V, Toplak H, Mitrakou A: Treatment modalities of obesity. Diabetes Care 2008; 31(suppl 2):S269-S272.

56 Mattila K, Haavisto M, Rajala S: Body mass index and mortality in the elderly. BMJ 1986; 292:876-878.

57 Rissanen A, Knekt P, Heliövaara M, Aromaa A, Reunanen A, Maatela J: Weight and mortality in Finnish women. J Clin Epidemiol 1991;44:787-795.

58 Carr DB, Utzschneider KM, Hull RL, Kodama K, Retzlaff BM, Brunzell JD, Shofer JB, Fish BE, Knopp RH, Kahn SE: Intra-abdominal fat is a major determinant of the National Cholesterol Education Program Adult Treatment Panel III criteria for the metabolic syndrome. Diabetes 2004;53:2087-2097.

59 Goodpaster BH, Krishnaswami S, Harris TB, Katsiaras A, Kritchevsky SB, Smansick EM, Nevitt M, Holvoet P, Newman AB: Obesity, regional fat distribution, and the metabolic syndrome in older men and women. Arch Intern Med 2005;165:777-783.

-60 Wadden TA, Berkowitz RI, Woble LG, Sarwer TB, Phelan S, Cato RK, Hesson LA, Osei SY, Kaplan R, Stunkard AJ: Randomised trial of lifestyle modification and pharmacotherapy for obesity. N Engl J Med 2005;353: 2111-2120.

61 Didangelos TP, Thanopoulou AK, Bousboulas $\mathrm{SH}$, Sambanis CL, Athyros VG, Spanou EA, Dimitiou KC, Pappas SI, Karamanos BG, Karamitsos DT: The ORLIstat and CARdiovascular risk profile in patients with metabolic syndrome and type 2 DIAbetes (ORLICARDIA) study. Curr Med Res Opin 2004; 20:1393-1401.
62 Van Gaal L: Reducing the cardiometabolic risk through selective antagonism of CB1 receptors. Clin Cornerstone 2002;6(suppl): S24-S29.

-63 Lakka TA, Laaksonen DE, Lakka HM, Männikkö N, Niskanen LK, Rauramaa R, Salonen JT: Sedentary lifestyle, poor cardiorespiratory fitness, and the metabolic syndrome. Med Sci Sports Exerc 2003;35:12791286.

-64 Strath S, Swartz A, Parker S, Miller N, Cieslik L: Walking and the metabolic syndrome in older adults. J Phys Act Health 2007;4:397410.

65 Short KR, Vittone JL, Bigelow ML, Proctor DN, Rizza RA, Coenen-Schimke JM, Nair KS: Impact of aerobic exercise training on age-related changes in insulin sensitivity and muscle oxidation capacity. Diabetes 2003;52:1888-1896.

-66 Orchard TJ, Temprosa M, Goldberg R, Haffner S, Ratner R, Marcovina S, Fowler S; Diabetes Prevention Program Research Group: The effect of metformin and intensive lifestyle intervention on the metabolic syndrome: the Diabetes Prevention Program randomized trial. Ann Intern Med 2005; 142: 611-619.

67 Eguchi K, Tomizawa H, Ishikawa J, Hashide S, Numao T, Fukada T, Shimada K, Kario K: Comparison of the effects of pioglitazone and metformin on insulin resistance and hormonal markers in patients with impaired glucose tolerance and early diabetes. Hypertens Res 2007;30:23-30.

68 Riddle MC, Drucker DJ: Emerging therapies mimicking the effects of amylin and glucagon-like peptide-1. Diabetes Care 2006;29: 435-439.

69 Cheng AY, Leiter LA: Implications of recent clinical trials for the National Cholesterol Education Program Adult Treatment Panel III guidelines. Curr Opin Cardiol 2006;21: 400-404.

70 Tomkin GH: Targets for intervention in dyslipidemia in diabetes. Diabetes Care 2008; 31(suppl 2):S241-S248.

71 Ferdinand KC: Management of cardiovascular risk in patients with type 2 diabetes mellitus as a component of the cardiometabolic syndrome. J Cardiometab Syndr 2006; 1: 133-140. 